\title{
EDITORIAL
}

\section{Inclusión de la perspectiva de género en la psicología: Una apuesta frente a la realidad del conflicto armado en Colombia}

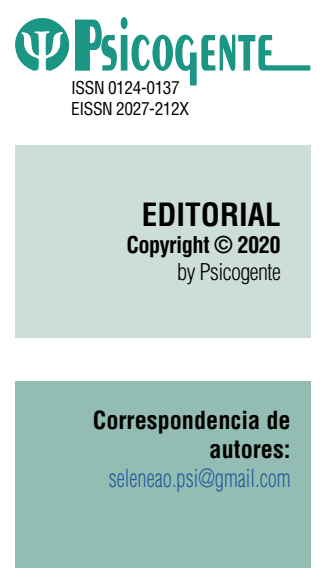

https://doi.org/10.17081/ psico.23.43.3780
Selene Margarita Ariza Ortiz (iD

Universidad Simón Bolívar, Colombia

En el ensayo El género: una categoría útil para el análisis histórico, la historiadora Joan Scott, (1986) hace una reflexión en torno a los usos del concepto género, cuestionando cómo el análisis histórico en su desarrollo carece de dicha perspectiva. Scott lo define al como una forma primaria de relaciones significantes de poder; distinguiendo cuatro elementos que le conforman: 1) Los símbolos y los mitos, 2) Los conceptos normativos, 3) Las instituciones y organizaciones sociales de las relaciones de género, y 4) La identidad. Dichos elementos se sitúan en el contexto social; de ahí que las representaciones en torno a la diferencia sexual como la feminidad y masculinidad nutran los intercambios de significados en el marco de las interacciones sociales, a la vez que las instituciones normativizan, condicionan o reproducen determinados símbolos en relación a esta diferencia.

En tal sentido, ha sido un desafío incorporar a partir del surgimiento de los gender studies a finales de los años 70, la categoría género en las investigaciones de las ciencias humanas y sociales. Para el caso de la psicología a pesar de que las reflexiones iniciales acerca del psiquismo humano desde el psicoanálisis se fundamentaron en la diferenciación sexual, es relevante denotar en la actualidad cómo esta disciplina se relaciona con los análisis de género y las apuestas feministas. A propósito, Reyes, Mayorga \& De Araújo Menezes (2017) señalan que esta relación implica cuestionar las epistemologías y metodologías a la hora de abordar ciertas problemáticas emergentes que están sujetas a transformaciones sociales, así como a contextos marcados por la desigualdad, la violencia y la opresión. Por ejemplo, es posible cuestionar la omisión de variables de orden demográfico y socioculturales que perpetúan la discriminación y los procesos de desigualdad, posibilitando su continuidad en los imaginarios sociales y en la producción científica de la disciplina.

Una apuesta crítica y ética para la psicología es valorar los aportes planteados desde los análisis de género, entre los que se encuentran: 1) La realización de 
investigaciones teniendo en cuenta las experiencias invisibles o invisibilizadas como problemas. Esto supone cuestionar qué conocimientos son los que se legitiman a nivel social dentro de las disciplinas y desde dónde son nombrados "los problemas sociales" que se buscan investigar. 2) La colonialidad del conocimiento, al reconocer las jerarquías de poder y de saber que el discurso feminista ha señalado como parte de las interacciones sociales, políticas, económicas y culturales, en las que la producción científica no escapa de tal configuración, favoreciendo la instauración de una lógica colonial, investigador/colonizador, que se traduce en cuestionar la posición de saber/poder con la cual se habla por los otros y se silencian ciertas voces. Por último 3) La interseccionalidad como una herramienta investigativa que favorece por un lado, la articulación de la psicología y el feminismo, y por el otro, entrevé cómo la organización social es un proceso complejo que no dependerá de un único aspecto sino de diversas construcciones sociales sobre las cuales también se sustentan las lógicas de la desigualdad y discriminación como la etnia y la clase social (Reyes, Mayorga \& De Araújo Menezes, 2017).

Teniendo en cuenta que el Colegio Colombiano de Piscología establece al menos 17 campos de análisis de la disciplina en Colombia, queremos resaltar cómo la inclusión de la perspectiva de género puede aportar a procesos de investigación en relación al conflicto armado, reconociendo, entre otros aspectos, el lugar de las mujeres, los impactos y los enfrentamientos a raíz de la violencia armada. Por ejemplo, en los campos de la psicología clínica, la psicología de la salud y la psicología social, un análisis de los impactos psicosociales y la salud mental de las mujeres a partir de la ocurrencia de hechos victimizantes en el marco del conflicto armado en Colombia, se hace necesario un primer reconocimiento de cómo el género configuró los roles y los lugares que desempeñaron hombres y mujeres en los territorios violentados por los actores armados; cómo desde esta diferenciación se estiman unas afectaciones que deben ser leídas desde una perspectiva diferencial, que dé cuenta de la desproporcionalidad de estos impactos, reconocidos así por la Corte Constitucional de Colombia en su jurisprudencia (2008).

Ahora bien, el género también moldea la forma cómo hombres y mujeres afrontaron la violencia; no es casualidad que las mujeres hayan sido en su mayoría quienes se desplazaron con sus hijos e hijas y demás familiares, esto sin descartar la posibilidad a otro tipo de vivencias. En efecto, muchas de ellas desempeñaron el rol de cuidadoras en sus hogares y esto implicó salvaguardar la seguridad de los miembros de la familia frente a la violencia armada, procurando su protección. Así, una respuesta que desde la psico- 
logía podría describirse como una reacción de huida o lucha frente al estrés, es menester comprenderla teniendo en cuenta las construcciones sociales del género que han ubicado históricamente a las mujeres en el rol de cuidadoras en nuestra sociedad.

De igual manera, cabe anotar que las representaciones de feminidad y masculinidad hegemónicas fueron reforzadas y reproducidas por los actores armados como formas de victimización a la población, a través de procesos de control sobre los roles, la vida social, los cuerpos y las sexualidades. La violencia sexual, por ejemplo, fue una forma de victimización de los actores armados que afectó en su mayoría a mujeres, niñas y personas LGBT. Lo anterior es clave para desarrollar procesos de apoyo y acompañamiento psicológico a personas que han sido víctimas de violencia sexual en el marco del conflicto armado, porque implica que la reelaboración del hecho traumático parta de una lectura del contexto, del significado del cuerpo de la mujer como escenario de disputa, de las transgresiones del orden heteronormativo, y por último, de considerar la intencionalidad particular de este tipo de violencia por parte de los actores armados en el marco de las luchas para el control del territorio.

Para concluir, la inclusión de la perspectiva de género en los diversos campos de la psicología, es una apuesta imprescindible de cara a brindar respuestas éticas y contextualizadas desde la investigación disciplinar y el acompañamiento profesional a los procesos de reparación a las víctimas y procesos de construcción de paz en Colombia.

\section{REFERENCIAS}

Reyes, María Isabel; Mayorga, Claudia; de Araújo Menezes, Jaileila(2017). Psicología y Feminismo: Cuestiones epistemológicas y metodológicas Psicoperspectivas, 16(2). pp.1-8. https://www.redalyc.org/articulo.oa?id=1710/171053168001 